\section{The wider implications of amphibian population declines}

Since the herpetological community first became aware of them in 1989, the sudden and catastrophic declines that have occurred among amphibian populations in many parts of the world have become the focus of intense research (DeWeerdt, 2001). What messages are there in the results of this research for the wider conservation community?

Many amphibians have declined, along with species belonging to other taxa, as the direct result of habitat destruction, degradation and change. While it is important to monitor such events, the primary focus of the Declining Amphibian Populations Task Force (DAPTF) is to investigate the numerous and wholly unexpected declines that have occurred within national parks, nature reserves and other protected areas, where habitat loss should not be a factor. The most obvious implication of these declines is that they raise serious doubts about the effectiveness of protected areas as a means for conserving biodiversity. As David Wake, one of the founders of the DAPTF, put it, 'putting a fence around biodiversity just isn't working'.

There have been two recurring features of amphibian declines in protected areas. Firstly, many have been very sudden, with populations disappearing over a period of 1 or 2 years. Secondly, while some amphibian species have been affected, others have not. These two features have helped to foster the implicit assumption that there is a single, globally acting cause for amphibian declines that affects only certain kinds of amphibian species. This concept of a 'smoking gun' has stimulated a great deal of innovative and exciting research into potential causes, notably increased UV-B radiation, climate change, pollution and disease. However, it is becoming increasingly clear that, while all these factors have played a part, to varying degrees in specific declines, no single factor can be held responsible for all amphibian declines. Indeed, there is increasing evidence that amphibian declines are caused by complex synergistic interactions between a number of causal factors. In a very recent study, Kiesecker et al. (2001) present evidence that, in the western USA, climate change and increased UV-B radiation have acted together to create circumstances in which amphibians are more likely to succumb to a pathogenic fungus. Another implication of amphibian declines, therefore, is that the causes of extinction are often not simple or obvious, and that we should not assume that similar phenomena have a common cause.

By focusing their attention on amphibians, there is a danger that researchers, like those working within the DAPTF, may come to assume that they are looking at phenomena that are unique to amphibians. This is clearly not the case. All the factors so far identified as being harmful to amphibians, such as UV-B, climate change and pollution, are harmful to other taxa. While the diseases that are harmful to amphibians, such as the fungal disease chytridiomycosis which is affecting amphibians throughout the world, is specific to amphibians, it is becoming increasingly clear that disease is a major threat to many wildlife populations. To give but two very recent examples, populations of vultures in India have been all but wiped out in the last 2 years, and a disease is currently sweeping through California's oak trees. Why wildlife populations seem to be becoming more susceptible to infectious disease in one of the major questions currently facing conservation biologists (Carey, 2000).

It is commonplace in reviews of amphibian declines, and particularly in grant applications, to see the argument that amphibians deserve special attention because they are especially sensitive to environmental degradation. This is based on particular features of their physiology, life history and habitat requirements. While there may be some merit in this argument, it is very clear that many other groups are undergoing a similar phenomenon. The World Wide Fund for Nature (WWF) maintains an index of biodiversity, categorized by habitat type (Loh, 2000). The index for freshwater habitats, based on time series data for 194 species of vertebrates, including amphibians, reveals a decline of $50 \%$ between 1970 and 1999 . This is a faster rate of decline than that for any other habitat type, including tropical forest. These data suggest that freshwater habitats are under particular threat, and that amphibians may thus be part of a much larger process. Among freshwater species, freshwater bivalves appear to be declining even more dramatically than amphibians and may thus have an even better claim for special attention.

The work of the DAPTF falls within the general area called Conservation Biology, but there is very little that we have been able to do that can truly be called 'conservation', in the sense that it seeks to reverse population declines. The reason for this is simple amphibian declines cannot be reversed until their causes 
are understood. What the DAPTF is doing is documenting, as fully as it can, one facet of the global decline in biodiversity, by recording and seeking to identify the causes of extinction events. Perhaps we should stop calling ourselves Conservation Biologists, and describe ourselves more accurately as Extinction Biologists.

Professor Tim Halliday, International Director, Declining Amphibian, Populations Task Force,

21 Farndon Road,

Oxford OX2 6RT, UK

e-mail: tim@toadhall.dircon.co.uk

\section{References}

Carey, C. (2000) Infectious disease and worldwide declines of amphibian populations, with comments on emerging diseases in coral reef organisms and in humans. Environmental Health Perspectives, 108 (Suppl. 1), 143-150.

DeWeerdt, S. (2001) Coordinating an international monitoring program. The Declining Amphibian Populations Task Force. Conservation Biology in Practice, Winter, 28-31.

Kiesecker, J.M., Blaustein, A.R. \& Belden, L.K. (2001) Complex causes of amphibian population declines. Nature, 410, 681-684

Loh, J., ed. (2000) Living Planet Report 2000. WWF International, Gland, Switzerland.

\section{Letter from the editor}

This issue of Oryx sees a number of changes. The Forum section makes its debut with If community conservation is the answer in Africa, What is the Question? by W.M. Adams and D. Hulme. This paper was identified as being controversial during the review process, and two replies were invited: Taking the broad view of conservation by David Western and Time to move Out of Africa! by Ashish Kothari. A further Forum paper is already lined up for the October issue, and I would welcome suggestions for suitable Forum topics and contributors for 2002.

Please note that the Instructions for Contributors to Oryx have been revised and extended, and can be found at the end of this issue. The Instructions are also available on the Oryx web page (http://www.blackwell-science. com/ory), as is the Code of Conduct for researchers contributing articles to Oryx (published in Oryx 35(2), 99-100) and the form that is used for the peer review of manuscripts.
I would like to take this opportunity to thank the Rufford Foundation for the financial support that they have been providing for Oryx. From December 2000 they have been supporting a half-time post of Editorial Assistant. This has been very ably filled by Dr Josephine Morley.

For those readers who regularly or occasionally send items for the Briefly section, please note that the deadline for submission for the October issue is 6 August. In the October issue we will publish the deadlines for 2002 .

Finally, Camilla Erskine left Oryx at the end of January, having seen Oryx through an important period in its development over the previous 18 months. As the incoming Editor I extend my thanks to her, both for her work with the journal and for ensuring a smooth handover to myself.

Martin Fisher 